\title{
Quartz Tuning Fork as Humidity Sensor
}

\section{Padmasine KG ${ }^{1 *}$ and Muruganand $\mathrm{S}^{2}$}

${ }^{1}$ Department of ECS, Karpagam University, Coimbatore, India

${ }^{2}$ Department of E\&I, Bharathiar University, Coimbatore, India

\begin{abstract}
This paper highlight, a novel and simple solution growth method to develop the deposition of nanocrystalline $\mathrm{ZnO}$ films on QTF to act as sensor, integrating merits of both SILAR and CBD techniques. The obtained film is characterized by high deposition rate, high film and used for the humidity sensing. And this chapter ends with the experiment done for measuring the frequency shift using PSoC and LabVIEW, which measures the shift in resonance frequency of QTFs due to the additional mass loading.
\end{abstract}

Keywords: PSOC; Lab view; SEM; XRD; Quartz tuning fork

\section{Introduction}

QTF coated with nanocrystalline $\mathrm{ZnO}$ thin film is used as humidity sensor and their humidity sensitivity characteristics have been investigated. It is experimentally demonstrated that QTF coated with nanocrystalline $\mathrm{ZnO}$ films shows the promising application for humidity sensor. The nanocrystalline $\mathrm{ZnO}$ thin films were deposited on the QTF by SILAR method followed by Chemical Bath Deposition. The film was characterized by X-ray diffraction (XRD) and Scanning Electron Microscopy (SEM) to obtain the information on the structural and morphological properties. And the humidity sensing characteristics of the sensors have been investigated. Sensing experiments were examined by measuring the shift in resonance frequency of QTF due to the additional mass loading. The results showed that the sensors had high humidity sensitivity, good stability, fast response time and well reproducibility.

\section{Experimental Details}

First nanocrystalline $\mathrm{ZnO}$ Seed layer is coated on thin film on QTF by SILAR method [1]. This thin film serves as a seed layer for the subsequent growth of nanorods in aqueous solutions at low temperature. The resulting films of highly ordered nanorods have the reproducibility and uniformity in large areas, which can potentially be employed in the development of electronics device like Humidity sensor (Figure 1) among several solutions for growth technologies, SILAR and CBD are two methods widely used to prepare $\mathrm{ZnO}$ layer from aqueous solution.

\section{Sensor configuration}

Preparation of seed layer using SILAR method: Quartz Tuning Fork, with resonance frequency of $32,678 \mathrm{~Hz}$ is used for this application as substrate. QTF is obtained by removing the metal lids and the tuning forks beam was exposed.

First, QTF has to cleaned to free from contamination, it is cleaned by placing it into acetone for $30 \mathrm{~min}$ and then washed by anhydrous ethanol and dried in a baking box. $\mathrm{ZnO}$ thin films were prepared by SILAR method followed by CBD to form the thin film on the QTF. As precursor zinc acetate dihydrates is dissolved into $100 \mathrm{ml}$ of absolute ethanol at $60^{\circ} \mathrm{C}$. After stirring for 1 hour, a clear and homogeneous solution was obtained, which acted as the precursor solution for QTF. Then after this by SILAR technique is followed. QTF is dipped for about 10 seconds. And then the coating was dried in the electronic furnace for $40^{\circ} \mathrm{C}$ to evaporate the ethanol solvent primarily [2]. After evaporation the ethanol solvent, the QTF have been subjected to annealing in the air in the electronics furnace at $350^{\circ} \mathrm{C}$ for 30 minutes. Then the white films were found on the surface of the QTF, these white films being the $\mathrm{ZnO}$ thin film.

Growth process in the SILAR method: Analytical reagents of zinc acetate dihydrate $\left(\mathrm{Zn}\left(\mathrm{CH}_{3} \mathrm{COO}\right)_{2} .2 \mathrm{H}_{2} \mathrm{O}\right)$ were dissolved in diluted ammonia to get zinc ammonium complex solution, which was then served as zinc cation precursor. Double distilled (DD) water kept at $80^{\circ} \mathrm{C}$ was used as anionic precursor. The SILAR growth involves in the subsequent immersion of cleaned QTF in cationic and anionic solution along with rinsing the QTF in between in DD water kept at room temperature. In the first step, the QTF was immersed in a beaker containing Zinc ammonium complex, where $\mathrm{Zn}^{2+}$ with ammonia formed zinc ammonia complex $\left(\left[\mathrm{Zn}\left(\mathrm{NH}_{3}\right) 4\right]^{2+}\right)$. In the first immersion process, zinc ammonia was adsorbed onto the QTF. In the second step, the zinc ammonia adsorbed QTF was immersed into the beaker containing DD water, where the a adsorbed zinc ammonia complex was converted into zinc hydroxide $\left(\mathrm{Zn}(\mathrm{OH})_{2}\right)$. As a third step, the $\mathrm{Zn}(\mathrm{OH})_{2}$ coated substrate was subjected to ultrasonic agitation to remove loosely bonded zinc hydroxide $\left(\mathrm{Zn}(\mathrm{OH})_{2}\right)$ molecules. Finally, the zinc hydroxide coated substrate was immersed into the DD water bath which was maintained at $80^{\circ} \mathrm{C}$, where $\mathrm{Zn}(\mathrm{OH})_{2}$ was converted in to solid $\mathrm{ZnO}$ film. Each immersion step took a time period of 40, 20, 70 and $20 \mathrm{~s}$ respectively [3]. A drying period of $15 \mathrm{~s}$ was maintained before the start of another deposition cycle. Figure 2 schematically shows the detailed SILAR procedure for the deposition of $\mathrm{ZnO}$ nanostructured seed layer thin films. In this present work, $\mathrm{ZnO}$ seed layer were deposited for 25 cycles.

$\mathrm{ZnO}$ nanorods growth by CBD process: In a typical synthesis process, $\mathrm{ZnO}$ seed layer film was used for the growth of $\mathrm{ZnO}$ nanorods by a simple CBD. The chemical bath aqueous solution was prepared by mixing equimolar $(0.05 \mathrm{M})$ aqueous solution of zinc nitrate hexahydrate $\left(\mathrm{Zn}\left(\mathrm{NO}_{3}\right)_{2} \cdot 6 \mathrm{H}_{2} \mathrm{O}\right)$ and hexamethylene tetra ammine (HMT) $\left(\mathrm{C}_{6} \mathrm{H}_{12} \mathrm{~N}_{4}\right)$. Then, ammonium hydroxide (28 wt\% $\mathrm{NH}_{3}$ in water) was added to alter the $\mathrm{pH}$ of the solution. The prepared $\mathrm{ZnO}$

*Corresponding author: Padmasine KG, Department of ECS, Karpagam University, Coimbatore, India, Tel: 914226471113; E-mail: padmasinekg@gmail.com

Received: September 13, 2016; Accepted: August 14, 2017; Published: August 21, 2017

Citation: Padmasine KG, Muruganand S (2017) Quartz Tuning Fork as Humidity Sensor. J Nanomed Nanotechnol 8: 451. doi: 10.4172/2157-7439.1000451

Copyright: $\odot 2017$ Padmasine KG, et al. This is an open-access article distributed under the terms of the Creative Commons Attribution License, which permits unrestricted use, distribution, and reproduction in any medium, provided the original author and source are credited. 
Citation: Padmasine KG, Muruganand S (2017) Quartz Tuning Fork as Humidity Sensor. J Nanomed Nanotechnol 8: 451. doi: 10.4172/21577439.1000451
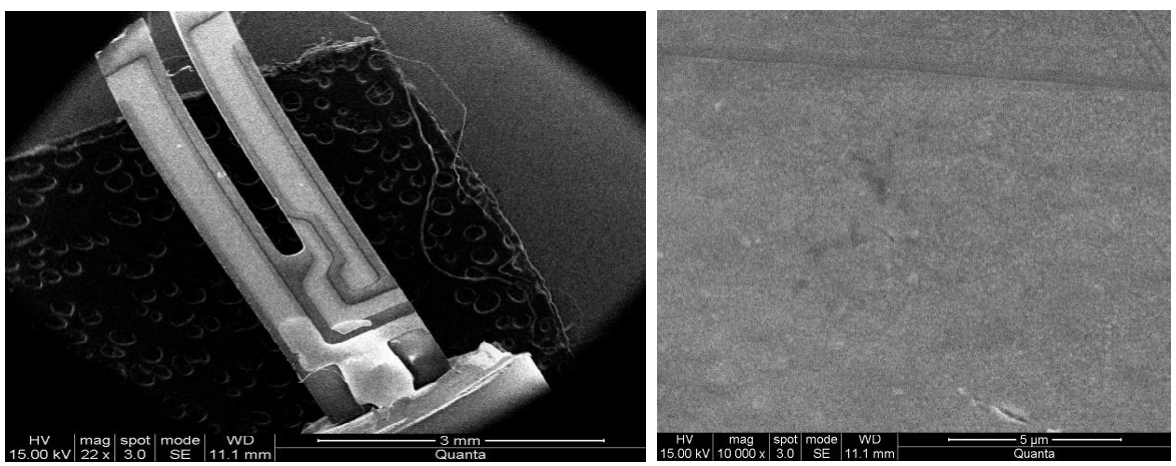

Figure 1: SEM picture of encapsulated QTF and uncoated QTF taken using ICON Analytical (FEI QUANTA 200) Scanning Electron Microscope.
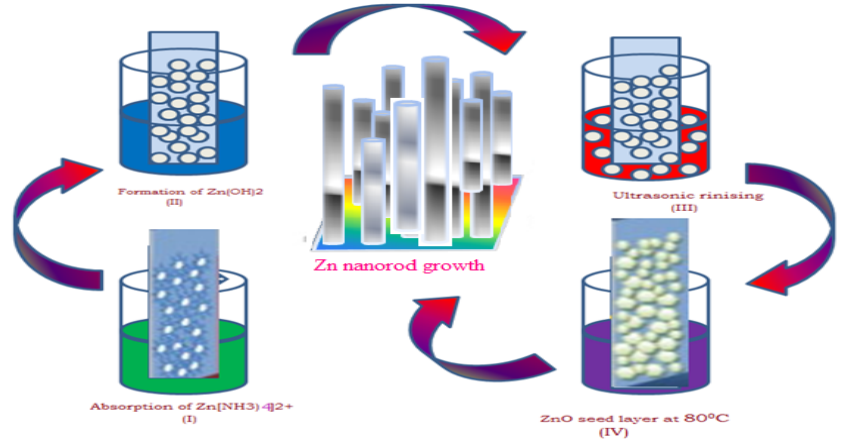

Figure 2: Schematic growth illustrations of $\mathrm{ZnO}$ nanorods.

seed layered substrates were placed vertically inside the chemical bath at a constant temperature of $70^{\circ} \mathrm{C}$ for $6 \mathrm{~h}$. After the completion of the reaction, the constant temperature bath is allowed to cool down to room temperature. Finally, as-grown CBD films were carefully washed with deionized water and acetone for several times to remove residual salts and then dried at room temperature for further characterization. Finally, $\mathrm{ZnO}$ nanorods stability behaviors were subjected to humidity sensing [4-7].

\section{Characterization studies of $\mathrm{ZnO}$ coated QTF}

The structural, morphological properties of QTF coated with Nanocrystalline $\mathrm{ZnO}$ using SILAR followed by CBD were examined by X-ray diffraction (XRD), Scanning Electron Microscopy (SEM) [8]. The XRD diffraction analysis is carried out using PANalytical (X'PERTPRO) X-Ray diffractometer with cu Ka radiation $(\lambda=1.54056 \dot{A})$. The SEM images were recorded using ICON Analytical (FEI QUANTA 200) Scanning Electron Microscope and particle seem to be uniform distribution of $\mathrm{ZnO}$ rods like crystal is formed on the layer of QTF. The humidity sensing is done by means of aqueous solution showered on the QTF which sense the humidity (Figure 3) and readied by coated QTF's shift in resonance frequency are measured using PSoC and Lab VIEW.

\section{Structure morphology analysis}

The XRD pattern of SILAR grown $\mathrm{ZnO}$ nanostructure seed layer deposited at 25 cycles (Figure 4). The XRD pattern from the deposition cycle has shown the diffraction peaks at $2 \theta$ equal to 34.64 , which is corresponding to $\left(\begin{array}{lll}0 & 0 & 2\end{array}\right)$ orientation of wurtzite hexagonal structure of $\mathrm{ZnO}$ (JCPD no.36-1451). In particular, it was clearly observed that the intensity of the $\left(\begin{array}{lll}0 & 0\end{array}\right)$ peak enhanced with the increase in the number

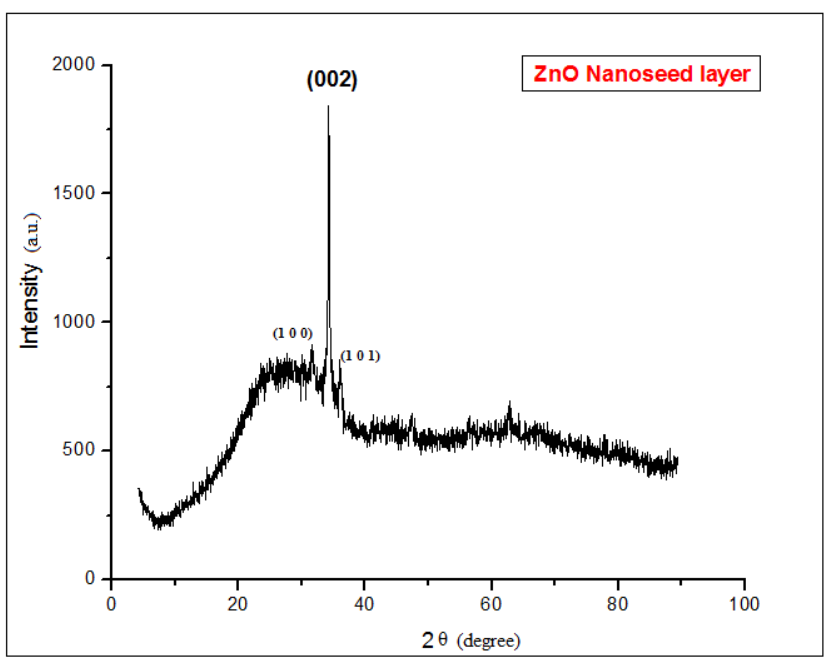

Figure 3: XRD pattern of SILAR grown $\mathrm{ZnO}$ nanostructure seed layer taken using PAN alytical (X'PERT-PRO) X-Ray diffractometer.

of deposition cycle. In addition to $\mathrm{ZnO}$ peak, a weak intensity peak corresponding to $\mathrm{Zn}(\mathrm{OH})_{2}$ phase has higher intensity compared to the higher deposition cycled films.

The XRD pattern of the $\mathrm{ZnO}$ nanostructured films grows using the CBD method (Figure 5). The $\left(\begin{array}{lll}0 & 0 & 2\end{array}\right)$ diffraction peak exhibited a higher intensity, showing a fact that the $\mathrm{CBD}$ grown $\mathrm{ZnO}$ is better aligned along ( $\left.\begin{array}{lll}0 & 0 & 2\end{array}\right)$ directions indicating that this particular seed layer condition is more suitable for the nanostructured films growth [9]. In addition to the $\left(\begin{array}{lll}0 & 0\end{array}\right)$ peak, we also observed other peaks such as $\left(\begin{array}{lll}1 & 0 & 0\end{array}\right)$, and $\left(\begin{array}{lll}1 & 0 & 1\end{array}\right)$ which are corresponding to the hexagonal $\mathrm{ZnO}$ phase. The diameters of the $\mathrm{ZnO}$ nanorods ranged (depending on the growth conditions) from only a few hundred nanometers to about 1 micrometer.

\section{Morphology analysis}

Seedlayer morphology: The SEM images of the $\mathrm{ZnO}$ nanostructured seed layer films prepares at deposition of 25 cycles and has random distribution of spindle like structures, randomly distributed spindlelike (i.e. having a circular cross-section and tapering towards each end) structure with length ranging from $100 \mu \mathrm{m}$ and has spot of 3.0 with magnification of 446 and formation of seed layer were observed (Figure 5). Further increase in the seed layer deposition cycle to 25 has resulted in random distributing of $\mathrm{ZnO}$ nanocrystals have hexagonal shape with uniform coating throughout the QTF. 
Citation: Padmasine KG, Muruganand S (2017) Quartz Tuning Fork as Humidity Sensor. J Nanomed Nanotechnol 8: 451. doi: 10.4172/21577439.1000451

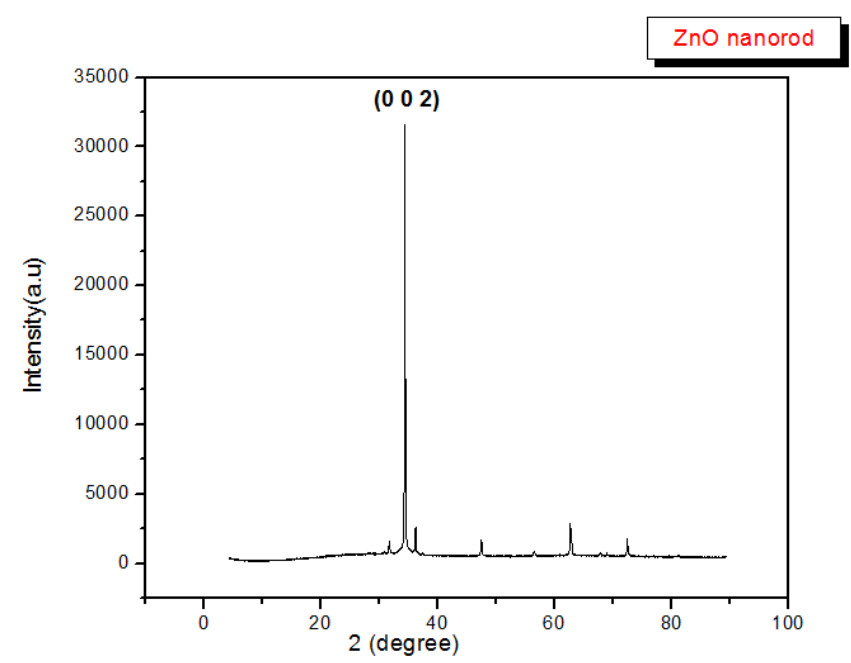

Figure 4: XRD pattern of nanocrytsalline ZnO nanorods deposited on the QTF.

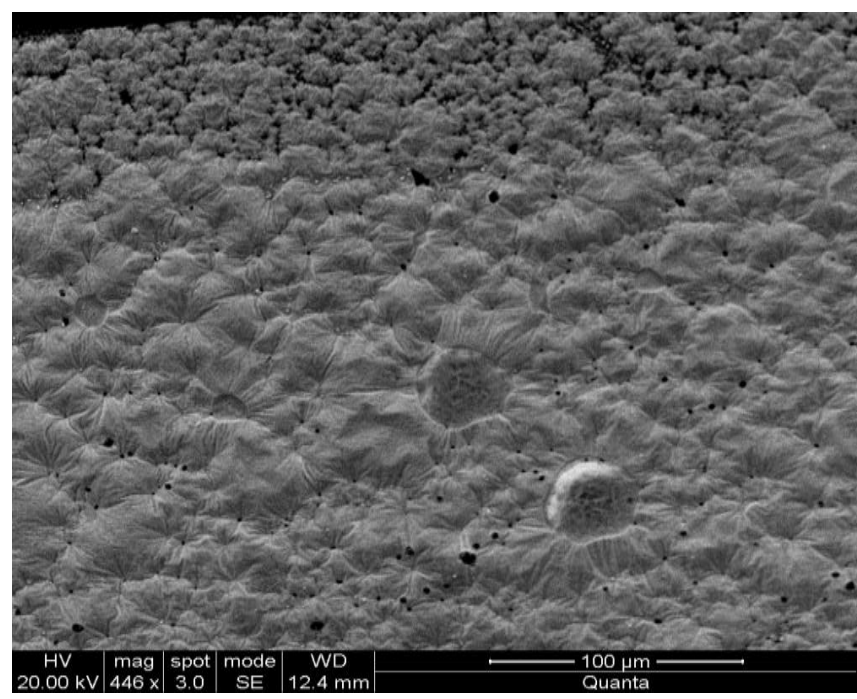

Figure 5: SEM of nanostructure seed layer growth on prepared by SILAR method using ICON Anakytical (FET QUANTA 200) Scanning Electron Microscope.

Nanorods growth morphology: Figure 6 shows the SEM image of $\mathrm{CBD}$ grown $\mathrm{ZnO}$ nanostructure film over a 25 cycle nanorods layer deposited on QTF. Interestingly the surface morphology shows vertically aligned $\mathrm{ZnO}$ which has magnification of 24,000 and spotted with 3.0 of $\mathrm{HV}$ of $25,00 \mathrm{kV}$ has the diameter range of $2 \mu \mathrm{m}$ observed to be uniform nanorods. From this observation we note that the seed layer deposition cycles is a key factor for the vertical growth of $\mathrm{ZnO}$ nanorods [10]. In general lower deposition cycle i.e. below 20 the cycle, $\mathrm{ZnO}$ seed layer growth is at an initial stage and therefore the orientation along $\left(\begin{array}{lll}0 & 0\end{array}\right)$ direction is very weak. But the when the deposition cycle is 25 cycle hexagonal shaped $\mathrm{ZnO}$ phase showed relatively strong XRD diffraction intensity along the $\left(\begin{array}{lll}0 & 0\end{array}\right)$ direction is proved to be sensitive towards the humidity.

Humidity measurement: When the saturated aqueous solution of $\mathrm{LiCl}, \mathrm{K}_{2} \mathrm{CO}_{3}, \mathrm{Mg}\left(\mathrm{NO}_{3}\right)_{2}, \mathrm{KCl}$ and $\mathrm{CuSO}_{4}$ is used in the closed glass vessel at the temperature of $25^{\circ} \mathrm{C}$ humidity environment is achieved. Using this environment [11-16], QTF is dropped into the solution. Humidity

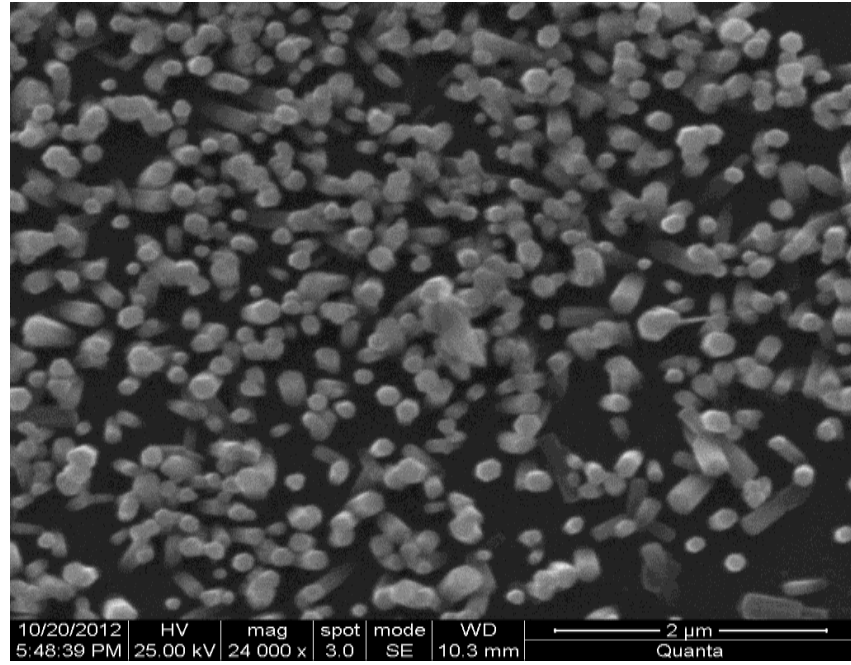

Figure 6: $\mathrm{ZnO}$ nanostructure of CBD growth SEM image.

\begin{tabular}{|l|c|}
\hline Mean frequency & $32765.39 \mathrm{~Hz}$ \\
\hline Standard deviation & 1.298187 \\
\hline Minimum & $32762 \mathrm{~Hz}$ \\
\hline Maximum & $32768 \mathrm{~Hz}$ \\
\hline
\end{tabular}

Table 1: Statistical details of the recorded data (300 reading has been taken).

will act on the coated layer and corresponding shift in frequency occurs. This oscillation is achieved due to the coating of nanocrystalline $\mathrm{ZnO}$ on QTF. Finally, it is sensed by PSoC, a menu driven graphical user interface program written in LabVIEW does on-line acquisition of QTF data, on-line plotting, saving the data in user specified file path has been carried out and the reading (Table 1).

\section{User interface in LabVIEW}

The values of frequencies measured on the PSoC are fed to a PC. The data is acquired by LabVIEW which offers a graphical user interface. A serial data acquisition module has been used in LabVIEW which collects data from a COM port. The block diagram and front panel of this VI has been illustrated in Figure 7. These values are displayed on the LabVIEW front panel and also a waveform chart is used to plot these data.

In this study QTF sensors were used to measure the response to the relative humidity. And the response of a blank uncoated QTF is also investigated to make sure that the sensing response to relative humidity is actual behavior of the $\mathrm{ZnO}$ film.

\section{Result and Discussion}

This related LabVIEW and graph can explain by a model based on the absorbed water and the mass increased on the beam of QTF. The deceased in shift in resonance frequency of the QTF with increased relative humidity in the film is related to the absorption of water vapor on the large film surface with capillary pores. The water molecules are absorbed on the grain surface and in pores. The higher surface area provides more suited for water absorption. When the QTF was placed in a humidity environment, the water molecules were absorbed on the surface of the film and in the pores. Then the mass on the QTF increased.ie resonance frequency of the QTF decreases. 
Citation: Padmasine KG, Muruganand S (2017) Quartz Tuning Fork as Humidity Sensor. J Nanomed Nanotechnol 8: 451. doi: 10.4172/21577439.1000451

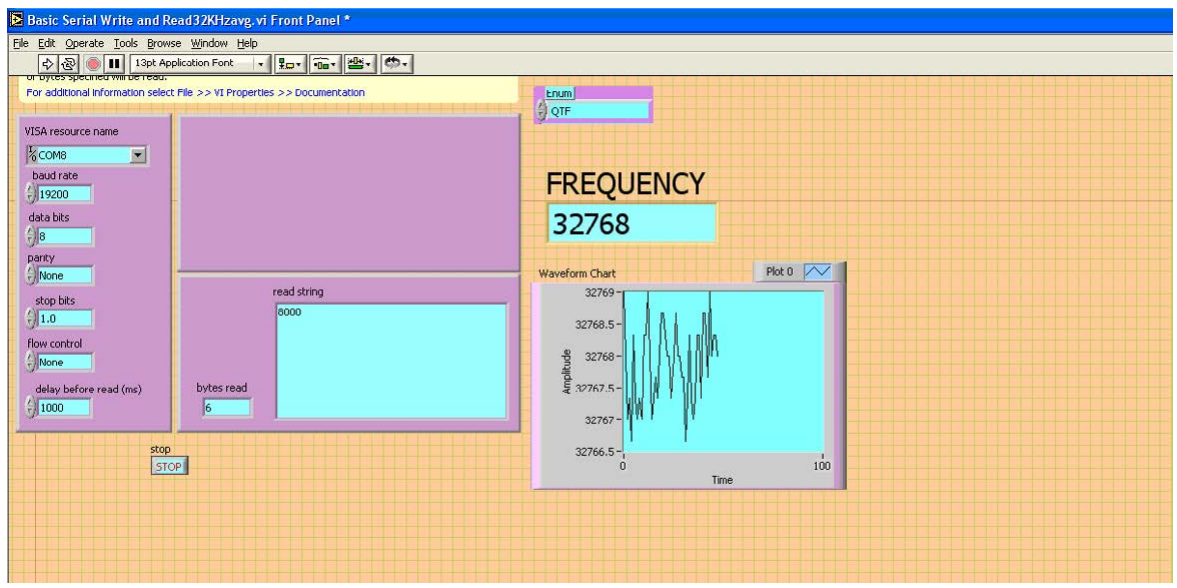

Figure 7: Front Panel of LabVIEW Program of PSoC embedded design for QTF for humidity measurement.

\section{References}

1. Shahi PK, Singh P, Singh AK, Singh SK, Rai SB, et al. (2016) A strategy to achieve efficient dual-mode luminescence in lanthanide-based magnetic hybrid nanostructure and its demonstration for the detection of latent fingerprints. $J$ Colloid Interface Sci 49: 199-206.

2. Jeyaraman J, Shukla A, Sivakumar S (2016) Targeted stealth polymer capsules encapsulating $\mathrm{Ln}^{3+}$-doped $\mathrm{LaVO}$ nanoparticles for bioimaging applications. ACS Miomater Sci Eng 2: 1330-1340

3. Singh LP, Jadav NV, Sharma S, Pandey BN, Srivastava SK, et al. (2015) Hybrid nanomaterials $\mathrm{YVO}_{4}: \mathrm{Eu} / \mathrm{Fe}_{3} \mathrm{O}_{4}$ for optical imaging and hyperthermia in cancer cell. J Mater Chem C 3: 1965-1975.

4. Kaczmarek, AM, Ndagsi D, Deun RK (2016) Dopant and excitation wavelength dependent color tunability in $\mathrm{Dy}^{3+}: \mathrm{YVO}_{4}$ and $\mathrm{Dy}^{3+} / \mathrm{Eu}^{3+}: \mathrm{YVO}_{4}$ microparticles towards white light emission. Dalton Trans 4: 6231-16239.

5. Ropp RC (1968) Spectra of some rare earth vanadates. J Electrochem Soc 115: $940-945$.

6. Xie L, Song H, Wang Y, Xu W, Bai X, et al. (2010) Influence of concentration effect and $\mathrm{Au}$ coating on photoluminescence properties of $\mathrm{YVO}_{4}: \mathrm{Eu}^{3+}$ nanoparticles colloids. J Phys Chem C 114: 9975-9980.

7. Ningthoujam RS, Rai SB, Dwivedi Y (2012) Nova Science Publishers Inc. Hauppauge, USA.

8. Singh LP, Ningthoujam RS, Srivastava SK, Mishra R (2014) Multifunctiona hybrid nanomaterials from water dispersible $\mathrm{CaF}_{2}: \mathrm{Eu}^{3+}, \mathrm{Mn}^{2+}$ and $\mathrm{Fe}_{3} \mathrm{O}_{4}$ for luminescence and hyperthermia application. J Phys Chem C 118: 1808718096.
9. Ghosh R, Pradhan L, Yensenbam PD, Meena SS, Tewari R, et al. (2011) Induction heating studies of $\mathrm{Fe}_{3} \mathrm{O}_{4}$ magnetic nanoparticles capped with oleic acid and polyethylene glycol for hyperthermia. J Mater Chem 21: 13388-13398.

10. Williamson GK, Hall WH (1953) X-ray line broadening from filed aluminium and olfram. Acta metall 1: 22-31.

11. William K (1987) Organic Spectroscopy Macmillan Educational Ltd., Houldmills, Hampshire.

12. Luwang MN, Ningthoujam RS, Srivastava SK, Vasta RK (2011) Preparation of white light emitting $\mathrm{YVO}_{4}: \mathrm{Ln}^{3+}$ and silica coated $\mathrm{YVO}_{4}: \mathrm{Ln}^{3+}\left(\mathrm{Ln}^{3+}=\mathrm{Eu}^{3+}, \mathrm{Dy}^{3+}\right.$, $\mathrm{Tm}^{3+}$ ) nanoparticles by $\mathrm{CTAB} / n$-butanol/haxane/water microemulsion route: energy transfer and site symmetry studies. J Mater Chem 21: 5326-5337.

13. Li J, Li JG, Liu S, Li X, Sun X, et al. (2013) Greatly enhanced Dy ${ }^{3+}$ emission via efficient energy transfer in gadolinium aluminate garnet $\left(\mathrm{Gd}_{3} \mathrm{Al}_{5} \mathrm{O}_{12}\right)$ stabilized with $\mathrm{Lu}^{3+}$. J Mater Chem C 1: 7614-7622.

14. Ningthoujam RS, Singh LR, Sudarsana V, Singh SD (2009) Energy transfer process and optimum emission studies in luminescence of core-shel nanoparticles: $\mathrm{YVO}_{4}: E u-\mathrm{YVO}_{4}$ and surface state analysis. J Alloy Comp 484: 782-789.

15. Blasse G, Grabmaier BC (1994) Luminescent Materials; Springer-Verlag Berlin.

16. Singh LP, Luwang MN, Srivastava SK (2014) Luminescence and photocatalytic studies of $\mathrm{Sm}^{3+}$ ion doped $\mathrm{SnO}_{2}$ nanoparticles. New J Chem 38: 115-121. 